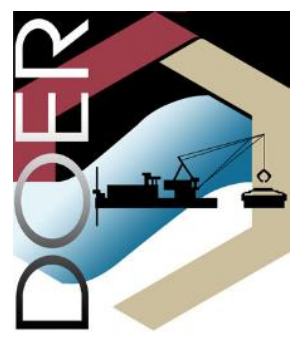

ERDC TN-DOER-R28

November 2019

\title{
Basics of Life-Cycle Assessment for Navigation
}

by Cate Fox-Lent, Matthew E. Bates, and Margaret H. Kurth

PURPOSE: This technical note (TN) describes how environmental life-cycle assessment (LCA) can integrate multiple environmental considerations and stakeholder constraints to inform and support sustainable operations and best practices for the U.S. Army Corps of Engineers (USACE) Navigation Program in a cost-effective manner.

BACKGROUND: The operations performed by the USACE civil works Navigation Program to maintain the nation's waterways for transportation have substantial commercial, national security, and recreational value. Decisions and policies about how the Navigation Program carries out its mission, while minimizing the cost of its operations and weighing numerous stakeholder commitments, are challenging. Over the past half century, stakeholder interests have continued to expand to include state and other federal resource agencies with water quality, air quality, and endangered species jurisdiction, citizen stakeholders and organizations with concerns for noise, environmental quality, and human health impacts, and federal requirements related to energy use and emissions. A formal method for measuring impacts of concern among these groups is LCA, which can be used for inventorying and assessing a broad range of environmental effects from navigation related activities. The LCA process provides the Navigation Program with an opportunity to understand its environmental footprint across the Nation, engage in a defensible and data-based conversation with resource agencies, and quantitatively compare and select best management practices among alternatives based on specific individual or overall estimated environmental and human health impacts.

INTRODUCTION: The USACE has long understood potential tradeoffs between environmental preservation and waterway navigability. Optimizing this trade-off is a key consideration as the USACE fulfills its Navigation mission, though it does present challenges. Current environmental modeling focuses on localized habitat changes, water quality effects, and bathymetric alterations. Where these types of environmental impacts are able to be quantified, they can also be mitigated. However, how do these local impacts compare to previously unmeasured effects at a regional level, or over the entire business line of the USACE Navigation Program? How do local restrictions on equipment use or placement areas accumulate impacts over time? The responsibilities of the USACE span city and state boundaries, and establishing affected parties and beneficiaries while making plans that affect them becomes increasingly challenging.

A tool that can help the USACE Navigation Program quantitatively recognize, minimize, and mitigate the impact of its activities on the environment is LCA. The USACE already has extensive experience with life-cycle costing in order to accurately estimate the burden of navigation projects on the agency's budget and to select cost-effective project alternatives. LCA is a similar process, but tracks environmental burdens (atmospheric, water, and terrestrial 


\section{ERDC TN-DOER-R28}

November 2019

emissions, energy and water consumption, and human health impacts). In addition to accounting for direct impacts from USACE activities, the analysis can extend to indirect impacts required by, or attributable to, those activities. For example, indirect "upstream" impacts of direct USACE activities might include those necessary to create the fuel and to mobilize resources for navigation projects. Similarly, indirect "downstream" impacts and benefits of USACE activities might include those related to sediment placement, beneficial use of dredged sediment, or the implications of reduced navigational depth on daily channel use. In this way, LCA allows system managers and planners to consider impacts that are often unseen at the point of use and occur over broader geographical areas and timescales. LCA can support district selection of management alternatives for specific projects and larger program policies to mitigate environmental impact and communicate options and decisions to stakeholders. New emphasis has been placed on inventorying and managing the life-cycle of navigation projects, as these maintenance actions often take place at regular intervals over an extended lifespan.

By inventorying and assessing the impacts of navigation activities, LCA can help address international, federal, and agency interest to monitor sustainability, conserve resources, and reduce the carbon footprint. These include interests to address environmental concerns through the conservation of energy, water, and waste (NREL 2010), "acquire supplies and services that promote energy and water efficiency, advance the use of renewable energy products, and help foster markets for emerging technologies" [23.202 Policy] (FAR 2009), and reduce the carbon footprint and greenhouse gas emissions of the nation (USDOS 2016). These and similar calls for sustainability accounting and analytics can be addressed through LCA, which has already been used by such agencies as the United States Department of Agriculture (USDA), National Energy Technology Laboratory, and the U.S. Environmental Protection Agency (USEPA) (www.lcacommons.gov) for topics ranging from comparing battery technologies to evaluating farming practices.

This document outlines the general components of LCA, highlights the benefits of incorporating LCA into operations decisions, describes opportunities for the Navigation Program to utilize LCA, and shows how LCA can support performance of the Navigation mission. Case studies from the Engineer Research and Development Center (ERDC) Environmental Laboratory (ERDC-EL) at the end of the document give specific applications of the method that illustrate how LCA can support the USACE Navigation mission in general.

LIFE-CYCLE ASSESSMENT (LCA): The International Standardization Organization (ISO) recognizes the use of LCA as an international analytic tool in its 14000 series for environmental management and sustainability (ISO 2006). LCA tracks the lifetime environmental impacts of a product or process for the purposes of improvement, public communication, or policy development. It is a method for inventorying and evaluating the environmental and human health burdens associated with multiple stages of a product or process's life, potentially including acquisition of raw materials, manufacture, transportation/distribution, use, maintenance, and disposal (Figure 1). The associated resource flows (i.e., energy, water, resources, etc.) and outputs (i.e., emissions, waste, etc.) result in quantifiable environmental and human health burdens. This systematic review of resource flows generates a comprehensive summary of both the local/immediate and distributed/longer term impacts of an operation and provides a means for comparing alternative management options. 


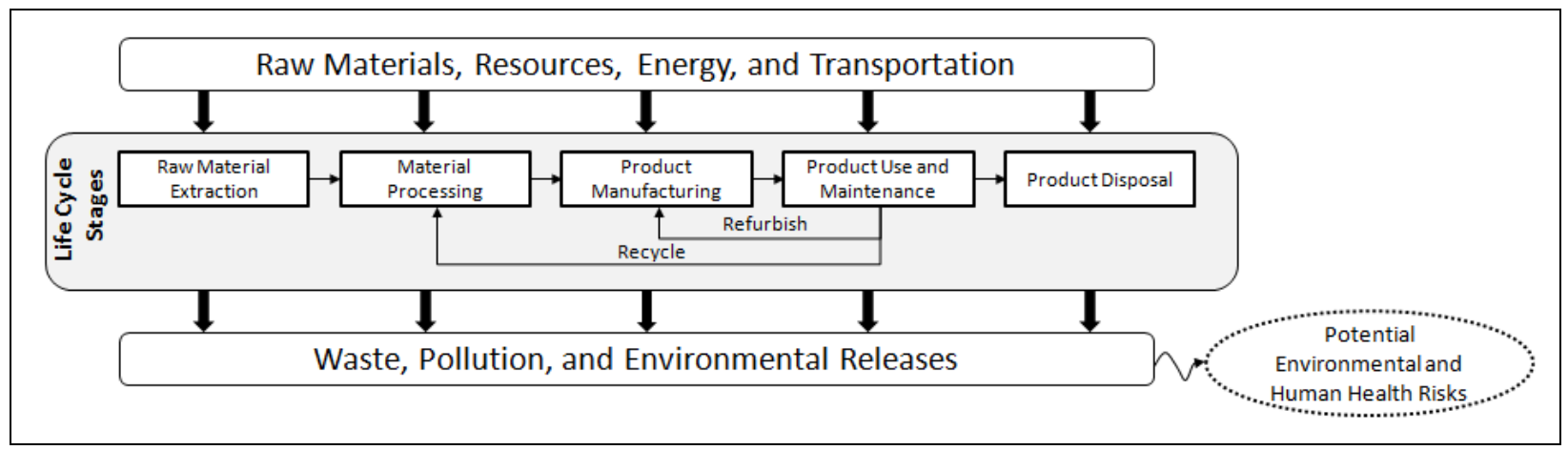

Figure 1. Life-cycle stages and corresponding inputs and outputs to the product.

Consideration of environmental impacts for navigation equipment and processes has generally been limited to those observed at the time of operation, such as the fuel consumed by a hopper dredge and the resulting emissions that are released. However, for a comprehensive inventory, the purview of impact accounting can be expanded from just the use-phase of dredging to encompass pre- and post-use phases (Figure 1). For example, instead of looking at the carbon dioxide emissions from the use-phase of a hopper dredge, LCA would inventory the emissions from the upstream and downstream equipment, activities, and dredging preparation, including dewatering, mobilizing, trips to disposal areas, pumping, capping, planting, grading, etc. This enables a more informed assessment of projects and project alternatives. In this way, LCA calculations can compare alternative plans based on estimated total impact per cubic yard (CY) moved, since consumption of energy, water, and other resources and the associated emissions to the atmosphere, land and water take place across many life-cycle stages.

LCA provides a unique contribution to the alternative selection process because it is specifically intended to assess environmental aspects that are absent from many traditional assessments. When paired with the other analyses that the USACE implements to assess the financial aspects of operations, LCA can help provide a more complete and accurate picture of the costs and benefits associated with alternative management options. This knowledge can assist the USACE Navigation Program to better incorporate environmental performance into the decision making process. At the project level, this may mean selecting an alternative that minimizes the aggregated emissions of an operation's life-cycle or some balance between minimizing local, immediate emissions and other distributed, long-term effects. At the program level, this may promote operational changes such as switching the fuel type used in the USACE-owned fleet, or prioritizing different types of dredges.

\section{BENEFITS OF LCA TO THE NAVIGATION PROGRAM}

LCA allows quantitative analysis of an activity's external impacts. LCA guides the user in quantifying and assessing the impacts of a product or process throughout its full lifecycle, incorporating upstream and downstream stages and impacts that may otherwise be neglected. This includes both local impacts (e.g., physical disruption to an aquatic ecosystem during management activities) and more global impacts (e.g., impacts from the transport of equipment) and is done in aggregate, including the repeat maintenance required over the lifetime of a project. The quantification is done per unit, based on the purpose or function of the product 
or process (e.g., per transport of one CY of dredged material), allowing comparisons to be easily made across alternatives. This "functional unit" based approach specifically helps when comparing alternatives of different volume or timing.

Management alternatives can inform issue-specific discussions with stakeholders. Illuminating impacts of particular concern allows them to be addressed, avoided, or mitigated. LCA lets the user choose impact categories to be included in the assessment in order to examine overall and specific burdens placed on human health, ecological health, or resource depletion. A planner can present results of individual impact categories, such as global warming potential, water use, or ecotoxicity, that align with specific management goals, as required by environmental policy or regulation, or to address the concerns of resources agencies for a particular form of environmental impact. When looking at multiple impacts, stakeholders can better understand tradeoffs between project alternatives across impact categories.

Another customization controlled by the user is the global, regional, or local scale at which the product or process in question is assessed. While global warming (via carbon footprint) is a common impact of interest in many LCA studies, more localized impacts such as air quality and water consumption can be used as a basis of comparison for management alternatives. Local and regional-scale impacts may be more salient to a particular stakeholders group, such as a local resource agency, while other nongovernmental organizations (NGOs) or public groups may be more interested in broad issues such as climate change and ozone impacts. Stakeholders with both local and broad concerns are common in Navigation Projects and may have competing interests. For example, using a clamshell dredge in one location may benefit a fish species, but may require greater fuel consumption and a longer duration of water quality impacts. LCA allows for quantification and comparison of these impacts so that an informed choice can be made by stakeholders and the USACE. Table 1 shows some of the commonly used impact categories along with the scale at which they are typically considered.

Heightened awareness of the impacts of industrialized activity on the environment has already brought a greater number of community participants to the decision process. It is important that USACE address their concerns so that Districts can maintain relationships with communities to facilitate continued success in the Navigation mission without the burden of legal action or highly restrictive permits. LCA, when paired with other tools that assess the financial aspects of operations, can help illuminate win-win alternatives that may not be apparent in the absence of a quantitative comparative assessment. 


\begin{tabular}{|c|c|c|}
\hline Impact category & Scale & Examples of life-cycle inventories (LCl) \\
\hline Global Warming & Global & $\begin{array}{l}\text { Carbon Dioxide }\left(\mathrm{CO}_{2}\right) \text {, Nitrogen Dioxide }\left(\mathrm{NO}_{2}\right) \text {, } \\
\text { Methane }\left(\mathrm{CH}_{4}\right) \text {, Chlorofuorocarbons (CFCs) }\end{array}$ \\
\hline Stratospheric Ozone Depletion & Global & $\begin{array}{l}\text { Chlorofluorocarbons (CFCs), Methyl Bromide } \\
\left(\mathrm{CH}_{3} \mathrm{Br}\right) \text {, } \\
\text { Hydrochlorofluorocarbons (HCFCs), Halons }\end{array}$ \\
\hline Acidification & Regional, Local & $\begin{array}{l}\text { Sulfur Oxides (SOx), Nitrogen Oxides (NOx), } \\
\text { Hydrochloric Acid (HCL), Hydroflouric Acid (HF) }\end{array}$ \\
\hline Eutrophication & Regional, Local & $\begin{array}{l}\text { Phosphate }\left(\mathrm{PO}_{4}\right) \text {, Nitrogen Oxide }(\mathrm{NO}) \\
\text { Nitrogen Dioxide }\left(\mathrm{NO}_{2}\right) \text {, Nitrates }\end{array}$ \\
\hline Photochemical Smog & Local & Non-methane hydrocarbon (NMHC) \\
\hline Terrestrial Toxicity & Local & $\begin{array}{l}\text { Toxic chemicals with a reported lethal concentrations } \\
\text { to rodents }\end{array}$ \\
\hline Aquatic Toxicity & Local & $\begin{array}{l}\text { Toxic chemicals with a reported lethal concentration } \\
\text { to fish }\end{array}$ \\
\hline $\begin{array}{l}\text { Particulate matter/respiratory } \\
\text { health }\end{array}$ & $\begin{array}{l}\text { Global, } \\
\text { Regional } \\
\text { Local }\end{array}$ & Total releases to air, water, and soil \\
\hline Resource Depletion & $\begin{array}{l}\text { Global, } \\
\text { Regional } \\
\text { Local }\end{array}$ & $\begin{array}{l}\text { Quantity of minerals used } \\
\text { Quantity of fossil fuels used }\end{array}$ \\
\hline $\begin{array}{l}\text { Land use, Habitat } \\
\text { creation/destruction }\end{array}$ & $\begin{array}{l}\text { Global, } \\
\text { Regional } \\
\text { Local }\end{array}$ & $\begin{array}{l}\text { Quantity disposed of in a landfill or other land } \\
\text { modifications }\end{array}$ \\
\hline Water Use & Regional, Local & Water used or consumed \\
\hline
\end{tabular}

LCA can inform project selection decisions and operational practices. In addition to comparing alternatives on the basis of total impact, LCA can be used to identify the most impactful stage in the life-cycle of a product and the environmental component that is most impacted at a particular stage or across the product's life cycle. This "hotspot" information can be used to choose a management alternative that will meet both USACE and stakeholder criteria or to guide modification of the life-cycle processes to prevent or mitigate the impact. Adoption of LCA can provide a systematic approach toward better navigation-management practices across the USACE. As information gaps are filled, better decisions can be supported and longterm management strategies enacted. For example, if one District finds that one dredge type or method is less harmful in an impact category of interest, then they can develop requests for bids in the dredge contracting process that specify requirements of the project to meet environmental goals. LCA can also facilitate other dredged material management decisions (e.g., open water versus upland placement, haul distances, rehandling requirements, etc.).

LCA METHODOLOGY: The ISO stipulates four general stages for conducting LCA (ISO 2006). These stages provides opportunities for the USACE to communicate with stakeholders to frame the analysis and reach conclusions on environmental concerns related to project planning. 
1. Goal and scope definition. Stating the goal of the study provides the context for the study. For example, the intent may be a comparison of two project alternatives, or it may be an investigation specifically into the human health impacts of a process. The goal identifies the type and precision of data necessary to provide meaningful results, establishes the common unit of measurement necessary for aggregation and comparison (i.e., functional unit), and guides how the results should be presented for the study audience. The scope of the study defines the geographical and temporal extent of the data to be collected and included in the analysis. This stage initially outlines any assumptions or limitations of the study (but note that life-cycle studies are typically iterative). The goal and scope can be revisited as more is learned in the inventory and impact assessment phases about the system under investigation. For example, the geographic scope of the inquiry can be adjusted to account for additional sediment placement/use sites that become of interest.

2. Inventory analysis. The inventory analysis is the most time-intensive step of a lifecycle study. In this stage, data is collected to construct a life-cycle inventory (LCI) of relevant material and energy flows during the life-cycle of the product or process in question. This includes the "amounts and kinds of material inputs and the types and quantities of energy inputs," as well as environmental releases to air, water, and land, quantified by type of pollutant (SAIC 2006). This is essentially a quantitative description of the life-cycle. As indicated in Figure 1, a life-cycle of a product or process generally includes the manufacture of any materials or infrastructure needed to create the product or perform the process, the upstream material extraction and processing, and the downstream use, maintenance and disposal or recycling. This can be a somewhat recursive problem (e.g., in that it takes refined petroleum fuel to run the machinery to extract and refine more petroleum from the earth). Hence the necessity of establishing the system boundary and scope of the study in first stage.

The inventorying process is a useful step (on its own) as it helps identify environmental releases that are often overlooked in standard environmental impact studies. For example, a traditional study may investigate the toxicity to fish species from exposure to chemicals in their environment. However, going upstream into the production process could identify the use of byproducts to make those chemicals that are also released into the groundwater system. Although these releases may occur in a different location and over a longer time period than the fish exposure, they are an important part of the life-cycle. The inventory is subject to decisions about the system boundary and data resolution, but is otherwise the main, objective accounting stage of LCA, analogous to the life-cycle costing process that a USACE District may undertake. Some studies stop at the inventory stage. These are called LCIs rather than LCAs.

Data for the inventory will usually need to be gleaned from a variety of sources, potentially including direct measurement, government agency reports, industry descriptions, and academic literature. To support the growing field of LCA, governments and organizations have begun to compile process data and detailed metadata into databases that are formatted and maintained specifically for LCA and similar sustainability analytic methodologies. The most prominent of these is the paid-access 
ecoinvent database, hosted by a consortium of Swiss institutions, although the U.S. National Renewable Energy Lab (NREL) and the USDA manage an open source U.S. LCI database, and many private firms have built smaller, industry-specific databases. The SiteWise LCA tool developed by the U.S. Navy, USACE, and the Battelle Memorial Institute for analyzing the footprints of contaminant remediation plans includes some inventory data for dredging-related processes (USNAVFAC 2015), and some process modules from the shipping and construction industries can also be modified to represent navigation equipment and processes. However, as dredging equipment is of particular importance to the USACE, investment in the development of a USACE-specific process database would enhance and streamline the ability to carry out life-cycle assessments.

3. Impact assessment. When the inventory is completed, satisfactory to the scope of the project, the data can be converted into environmental burdens using characterization factors. These factors transform raw flows into more substantive information that convey the implications of those flows for environmental or human health. Impact assessments can conclude with midpoint or endpoint indicators, depending on the goal and audience for the study. Midpoint indicators result from transforming all flows of the same impact category into a single equivalent unit for the purpose of aggregation. For example, masses of phosphate, ammonia, and nitrates may all be converted into equivalent masses of $\mathrm{PO}_{4}$ to indicate the total freshwater eutrophication potential. Some impact assessment methods extend this analysis to an endpoint indicator. Here, the mass of $\mathrm{PO}_{4}$ equivalents for the study process is compared to the total release of $\mathrm{PO}_{4}$ equivalents for the industry, region, country, or world in order to determine the relative magnitude of impact the study release is likely to have on the overall eutrophication of the system, compared to other well-known sources.

There are numerous impact assessment methods using different but comparable characterization factors, indicators, and reference environmental releases. The USEPA has developed the Tool for the Reduction and Assessment of Chemical and other environmental Impacts (TRACI) to facilitate the characterization of midpoint indicators of environmental impacts for the U.S. Impact assessment methods generally include indicators of atmospheric impacts, aquatic and terrestrial toxicity, carcinogenic, noncarcinogenic, and respiratory health impacts for humans, and depletion of non-renewable energy and material resources from the earth. Table 1 provides examples of impact categories, data, and characterization factors. These impact categories include local (e.g., terrestrial ecotoxicity) and global (e.g., global warming) impacts of both immediate (e.g., respiratory particulate matter) and long-term (e.g., ozone depletion) consequence. Different impact assessment methods can also provide multiple weighting schemes, where long-term vs. short-term and local vs. global impacts are given equal consideration, or where some impacts are emphasized or discounted relative to others. Appropriate impact assessment methods are selected based on the goal, scope, and audience of the study.

In addition to direct impacts of a process or product life-cycle on the environment and human, indirect effects also occur via ecosystems. Those impacts have the potential to diminish or enhance the provision of goods and services by ecosystems. Ecosystem 
services refer to the numerous benefits that humans derive from the existence of ecosystems and their functioning. The concept is established as a mechanism for valuing the production of goods and services by natural capital (Kareiva et al. 2011) into traditional ways of capital accounting. The objective of formalizing the flow and value of benefits from ecosystems to society in ecosystem services accounting is highly consistent with the objective of LCA to account for impacts. For example, where ecosystem services analyses account for the provision of water of a suitable quality, LCA considers the potential to degrade natural functions by contamination. Integrating an ecosystem services lens with LCA can enable the translation of specific human activities to impacts on the natural capital.

4. Interpretation/Comparative. The interpretation of LCA results communicates tradeoffs between impacts to non-expert decision makers and stakeholders, similar to a Net Environmental Benefits Analysis. Interpretation of the study for this audience should include a discussion of how the definition of the scope and system boundary and selection of the impact assessment method affect the results. It should also be understood that LCA is meant to help capture the magnitude and multitude of impacts across the full life-cycle of a product or process. Characterization factors are, therefore, necessarily generalized for broad application rather than for specific species, location, temperature, and other conditions. Nonetheless, in many cases, LCA can be reasonably used to comparatively evaluate alternatives. If these alternatives have been assessed using the same system assumptions and impact assessment method, the relative differences in the results can be highly informative, since the use of consistent metrics ensures an equitable comparison of alternatives. If the initial interpretation identifies unknown or unexpected scales of impact, redefinition of the goal, scope, or LCI may be needed to evaluate those impacts. The ability to do sensitivity analysis during the interpretation stage is another important benefit of LCA application. This can establish which components of the lifecycle have the greatest effect on overall results, which can in turn drive re-imagination and improvement of the alternatives.

\section{APPLICATION OF LCA AND CASE STUDIES FOR THE NAVIGATION PROGRAM: LCA has been widely applied by national and global consumer goods corporations to track the environmental footprint of their entire supply chain, for use alongside financial and economic data to optimize production process for both sustainability and profitability. Less work has been done to date to document and analyze the life-cycle of navigation related activities. Below are summaries of three case-studies from the ERDC-EL that demonstrate the potential range of applications of LCA to the Navigation Program.}

Diesel and Biodiesel use in Navigation Equipment. Tubman et al. (2016) measured emissions from the operation of USACE-owned debris boats using three different fuels, to explore the utility of using biofuels in navigation equipment to reduce carbon emissions and increase use of renewable resources. This was valuable for documenting use-stage outputs. However, by not using LCA, upstream impacts were ignored (and the upstream environmental impacts of fuel consumption vary widely). Tsang et al. (2015) expanded this work to develop an LCA of their three studied fuels: conventional diesel (CD), 100\% soybean-based biodiesel (SB), and a 50:50 blend of algae-based biodiesel (ABB) and military diesel. The study examines 
impacts across life-cycle stages of each fuel to formulate a comprehensive picture of the environmental/health implications of choosing a fuel, from petroleum extraction and soybean and algae feedstock growth, to plant oil extraction and fuel refining, and ultimately combustion during the use-phase. The midpoint impact results across ten categories for the two biodiesels, benchmarked against traditional diesel, are shown in Figure 2. Although the initial investigation by Tubman et al. (2013) indicated that carbon dioxide emissions were indistinguishable across the fuel types, the LCI and LCA show that the use of soybean-derived biofuel has the potential to reduce life-cycle global warming impacts, but perhaps at the expense of greater ecosystem and human health impacts. An additional result of the study broken down by process stage showed that the higher impacts from algal fuel in some categories are largely due to feedstock growth and oil extraction activities. Algal fuel is an emerging industry, and process improvement and economies of scale may reduce these impacts in the futures.

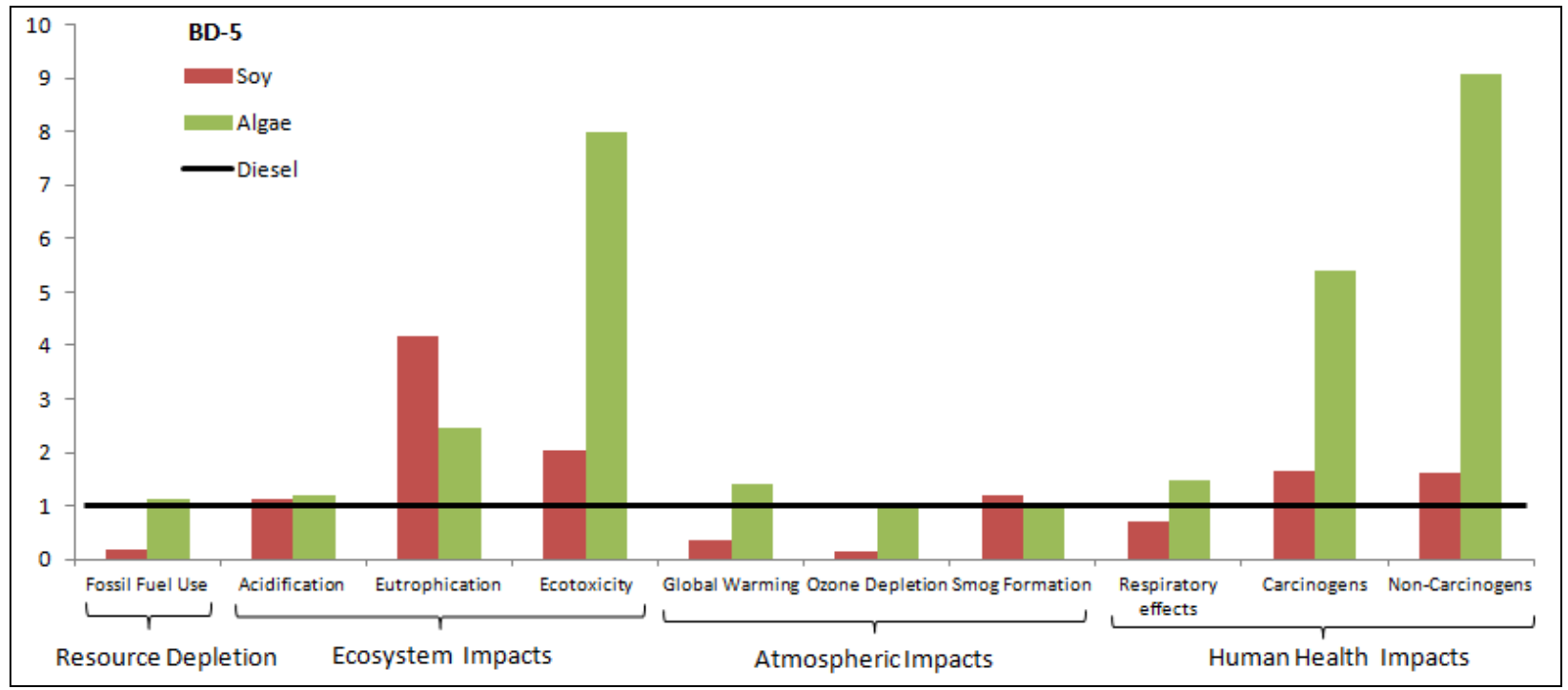

Figure 2. Impact assessment results for soybean-based biodiesel and a 50:50 blend of algae-based biodiesel and military diesel, benchmarked against the impacts of conventional diesel in each category (Tsang et al. 2015).

Dredged Sediment Placement Strategies. In the Long Island Sound (LIS) region of New York, Connecticut, and Rhode Island, many environmental stakeholders have expressed a preference for upland disposal of dredged sediment, even though it is a more expensive option than in-water placement. Bates et al. (2014) applied LCA to compare the life-cycle environmental and human health impacts of three types of placement alternatives: open water, upland, and a near-shore containment island, for uncontaminated dredged material from LIS. This provides data on the long-term and distributed impacts of each placement strategy that may also be of interest to decision makers and environmental stakeholders, but which had not been traditionally considered in relation to dredged material management in that region. A detailed breakdown of activities required for each placement option in the LIS region was developed in collaboration with the USACE New England District's cost-engineering department to create a process map and system boundary (Figure 3). The main life-cycle activities that contribute to ecosystem, human health, and resource consumption impacts identified in the study include: extracting raw materials from the earth, producing and using the equipment and fuel needed to 
construct the placement sites, handling and transporting the dredged material, and eventually disposing of the equipment and resources used in the process.

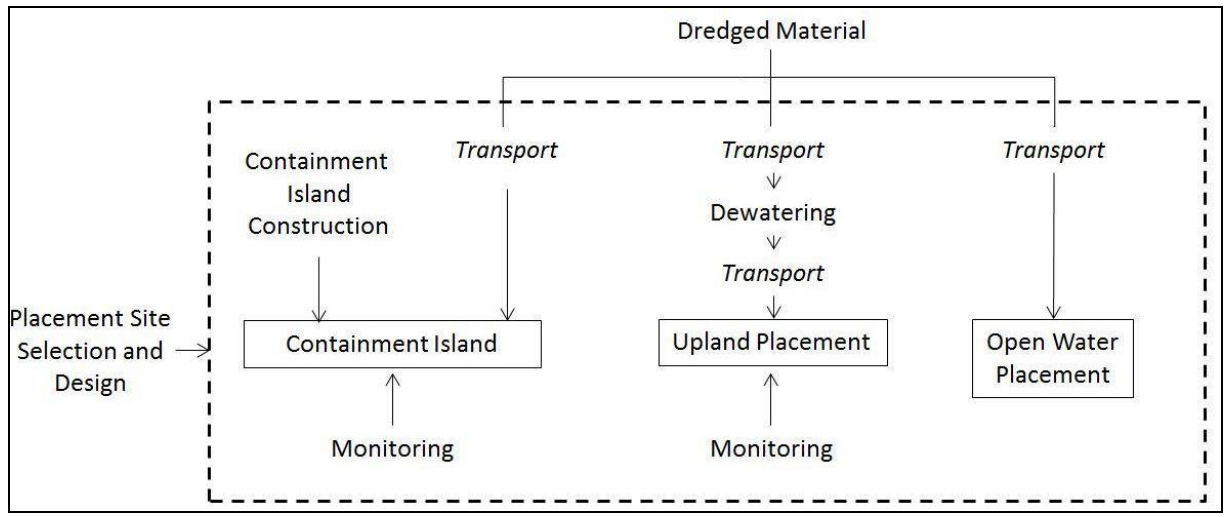

Figure 3. Activities associated with three alternative methods of dredged material placement. Dashed line denotes the system boundary (Bates et al. 2014).

Quantitative accounting of each of these activities shows impacts associated with fossil fuel combustion (climate change, particulate matter, and non-renewable resource depletion) as major impacts of placement actions. In terms of these metrics, open water placement is less environmentally burdensome due to the dewatering and construction processes, less-efficient transportation modes, and/or extended distances required for the other types of placement sites (Figure 4).

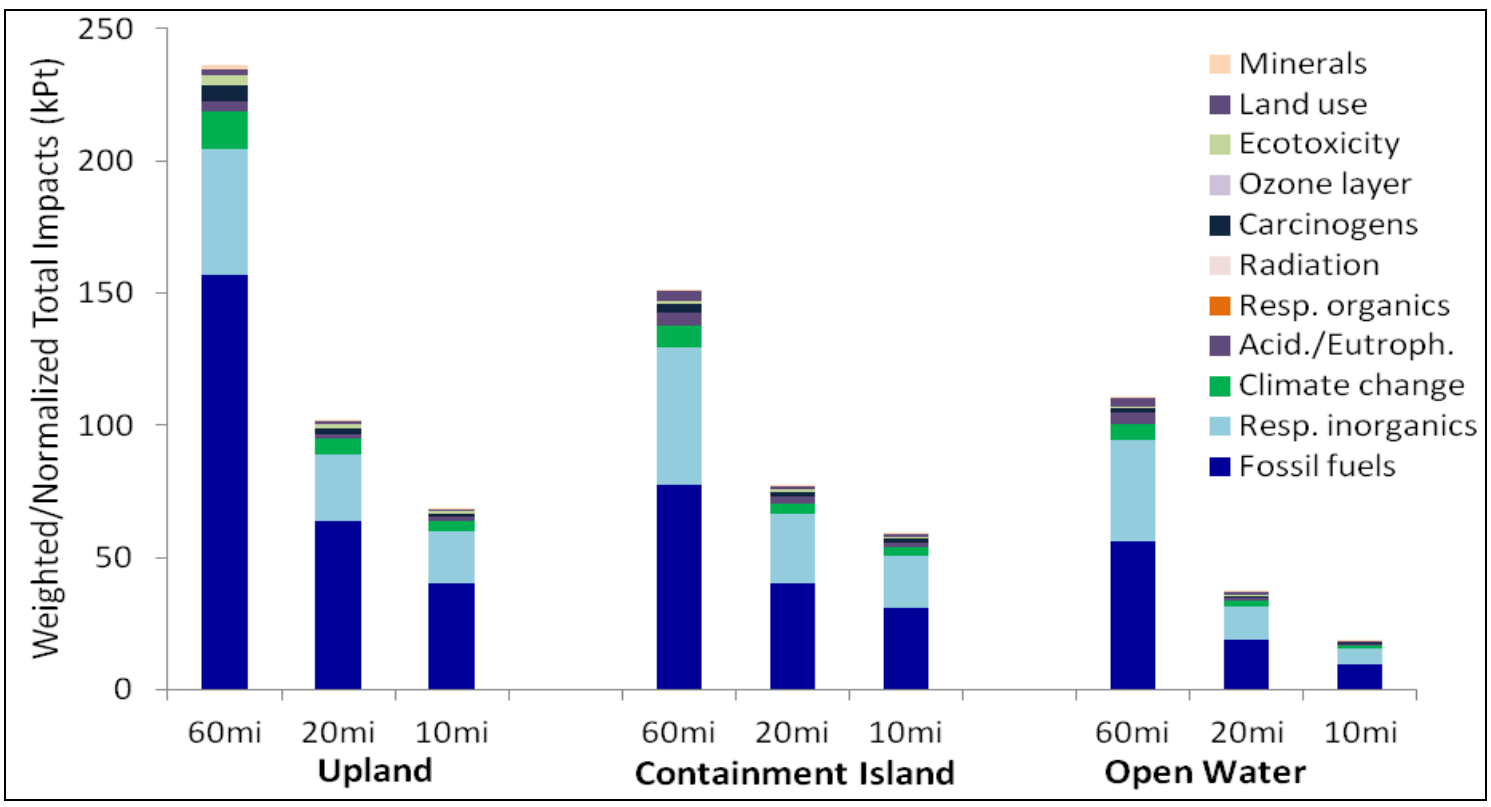

Figure 4. Normalized impacts for three placement alternatives at 10, 20, and 60 miles from the dredge site. Endpoint impacts are weighted using the Eco-indicator 99 hierarchist method to generate single-score (kPt) values (Bates et al. 2014). 
Contaminated Sediment Remediation. Sparrevik et al. (2011) applied LCA to evaluate the full environmental footprints of four management alternatives for capping contaminated sediments in Grenland Fjord, Norway. Remediation alternatives are traditionally chosen on the basis of minimizing the risk associated with contamination to humans and ecosystems. As the study demonstrates, LCA offers the opportunity to extend the appraisal of alternatives by including the impacts of those alternatives over the course of their life-cycle. The magnitude of environmental hazards that are incidental or secondary to the remediation activity (e.g., capping material production or energy requirements) can be used as an additional basis for comparison (Figure 5). Three types of remediation were considered for the industrially-contaminated Grenland Fjord including capping with locally dredged clay, crushed limestone from a regional source, or activated carbon. The LCA investigates the environmental footprint of these three management alternatives plus natural resedimentation (a natural recovery scenario). Impacts to the fjord system originating from the action of reducing risks associated with contaminated material are categorized as primary, and those related to resource and energy use during cappingmaterial creation and preparation as secondary.

Considering only the primary impacts associated with the effort to reduce human health risk, active methods were found to be preferable. When the full life-cycle environmental footprint of the alternatives are considered, however, natural recovery methods performed slightly better than most active remediation due to the contrast in the amount of energy and resources necessary. Capping with newly mined activated carbon carried a far greater footprint than other capping methods, including the use of activated carbon from biomass souces (Figure 6). These results show that the preferred alternative depends on the scope and the impact categories that are the focus of the study as well as stakeholder values and preferences, but that the selection of an alternative can be more fully informed by these quantitative methods.

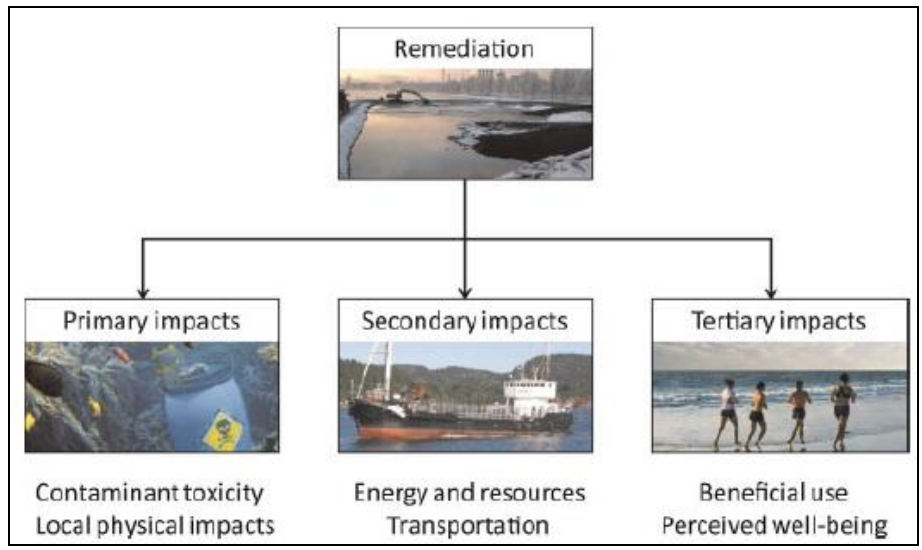

Figure 5. Adapting the impact framework for LCA effect characterization to sediment remediation at contaminated sites (Sparrevik et al. 2011). 


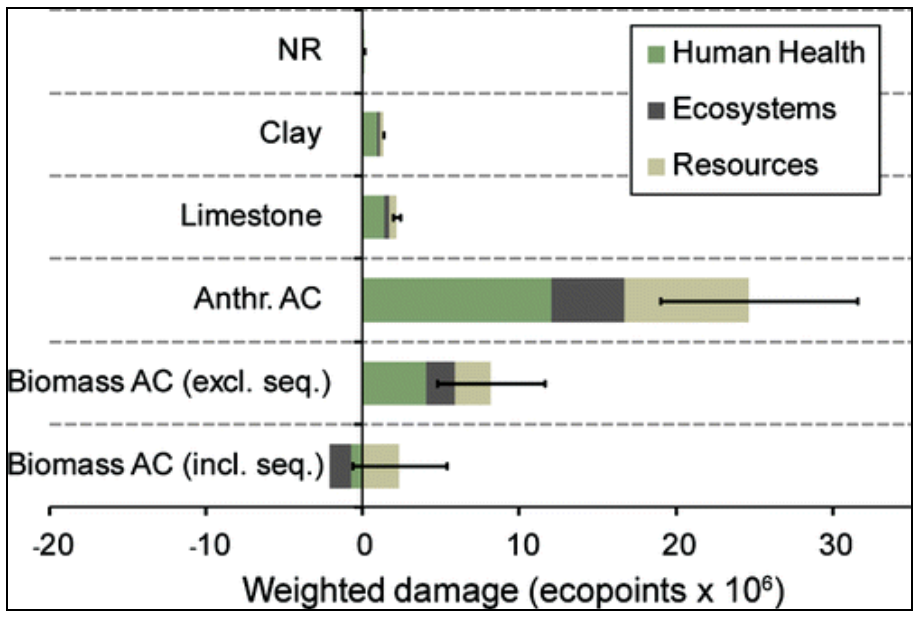

Figure 6. Normalized and weighted results (ecopoints) obtained using the ReCipe hierarchist end-point impact aggregation method with the European normalization values and the average weighting set (Sparrevik et al. 2011).

CONCLUSION: LCA is an analytic tool for measuring both local/immediate and broad/distributed environmental and human health impacts associated with a product or process. It can be a useful tool for assessing environmental impacts not previously considered in the USACE Navigation operations and may enable more effective communication with stakeholders. As more dredging-related LCA studies are developed, they can inform dredging planning and the development of innovative, improved project alternatives that better minimize a broad range of impacts, are attuned to larger Navigation Program goals, and that respond to both USACE and stakeholder concerns. Data for future LCA analyses related to dredging and sediment management are uniquely available to USACE, which presents opportunities for future knowledge advancement to inform sediment management.

\section{REFERENCES}

Bates, M. E., C. Fox-Lent, L. Seymour, B. A. Wender, and I. Linkov, I. 2014. Life cycle assessment for dredged sediment placement strategies. Science of the Total Environment 511: 309-318.

Federal Acquisition Regulation (FAR). 2009. Federal Acquisition Regulation, Volume I and II, August 2009.

International Organization for Standardization (ISO) 2006. ISO 14040:2006 Environmental management - life cycle assessment - principles and framework. Geneva, Switzerland.

Kareiva, P., H. Tallis, H., Ricketts, T. H., Daily, G. C. and S. Polasky. 2011. Natural capital: Theory and practice of mapping ecosystem services. Oxford, UK: Oxford University Press.

National Renewable Energy Laboratory (NREL). 2010. Net zero energy military installations: A guide to assessment and planning. Washington, DC: NREL/TP-7A2048876.

Scientific Applications International Corporation (SAIC). 2006. Life cycle assessment: Principles and practice. Cincinnati, OH: U.S. Environmental Protection Agency Office of Research and Development National Risk Management Research Laboratory.

Sparrevik, M., T. Saloranta, G. Cornelissen, E. Eek, A. M. Fet, G. D. Breedveld, and I. Linkov. 2011. Use of life cycle assessments to evaluate the environmental footprint of contaminated sediment remediation. Environmental Science and Technology 45(10): 4235-4241. doi: 10.1021/es103925u. 


\section{ERDC TN-DOER-R28}

November 2019

Tsang, M., C. Fox-Lent, S. Wallace, T. Welp, M. Bates and I. Linkov. 2015. Life-cycle impacts of soybean and algae biodiesel: Case study of U.S. marine vessels. Biofuels, Bioproducts and Biorefining 9(5): 567-580. https://doi.org/10.1002/bbb.1569.

Tubman, M., T. Welp, R. Immel, and R. Leitch. 2016. Evaluation of Biodiesel Fuels to Reduce Fossil Fuel Use in Corps of Engineers Floating Plant Operations. ERDC/CHL TR-16-11. Vicksburg, MS: United States Army Corps of Engineers. http://www.dtic.mil/get-tr-doc/pdf? AD=AD1013241.

U.S. Army Corps of Engineers (USACE). 2009. Long Island Sound Dredged Material Management Plan: Dredging Needs Report. Prepared for the U.S. Army Corps of Engineers under Contract No. DACW33-03-D-0004, Delivery Order No. 43. http://www.nae.usace.army.mil/Portals/74/docs/topics/LISDMMP/DredgingNeeds.pdf

U.S. Department of State (USDOS). 2016. U.S.A. First NDC Submission. Report to the United Nations Framework Convention on Climate Change. http://www4.unfccc.int/ndcregistry/PublishedDocuments/United\%20States \%20of\%20America\%20First/U.S.A.\%20First\%20NDC\%20Submission.pdf.

U.S. Environmental Protection Agency (USEPA). 2006. Life cycle assessment: Principles and practice. EPA/600/R06/060. Washington, DC: National Risk Management Research Laboratory. Contract No. 68-C02-067.

U.S. Naval Facilities Engineering Command (NAVFAC). 2015. SiteWise Version 3.1 User Guide. https://www.navfac.navy.mil/content/dam/navfac/Specialty\%20Centers/Engineering\%20and\%20Expeditionar \%\%20Warfare\%20Center/Environmental/Restoration/er pdfs/s/SiteWise3.1/sitewisetm user quide Version\% 203\%201 20150924.pdf.

NOTE: The contents of this technical note are not to be used for advertising, publication, or promotional purposes. Citation of trade names does not constitute an official endorsement or approval of the use of such products. 